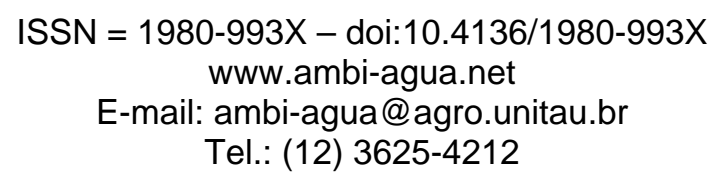

\title{
Potencial mutagênico dos poluentes na água do rio Paraíba do Sul em Tremembé, SP, Brasil, utilizando o teste Allium cepa
}

(doi:10.4136/ambi-agua.176)

\author{
Leonardo Maurer de Oliveira ${ }^{1}$; Júlio Cesar Voltolini' ${ }^{2}$; Agnes Barbério ${ }^{3}$ \\ Universidade de Taubaté (UNITAU) \\ E-mail: ${ }^{1}$ leonardo.biologia@yahoo.com.br; ${ }^{2}$ jcvoltol@uol.com.br; ${ }^{3}$ agnesbarberio@yahoo.com.br
}

\section{RESUMO}

A mutagenicidade pode estar relacionada com quebras cromossômicas induzidas por poluentes ambientais. $\mathrm{O}$ objetivo deste estudo foi caracterizar o potencial mutagênico dos poluentes presentes na água do rio Paraíba do Sul, cidade de Tremembé - SP, analisando alterações cromossômicas em células meristemáticas de Allium cepa, no verão (abril) e inverno (agosto) de 2008. Os bulbos foram expostos aos tratamentos por $72 \mathrm{~h}$ : água do rio, solução de Hoagland (controle negativo) e $15 \mu \mathrm{g} / \mathrm{L}$ de MMS - metilmetanosulfonato (controle positivo). Em cada tratamento, 3 bulbos foram expostos, para cada bulbo, 5 lâminas foram confeccionadas. Para análise do índice mitótico (IM) e frequência de micronúcleos (MN) foram analisadas 2.000 células por raiz/lâmina e 100 células para aberrações cromossômicas (AC). Em abril, os poluentes exerceram alto potencial mutagênico nas células meristemáticas de A. серa, a frequência de $\mathrm{MN}$, stickiness (cromossomos pegajosos) e $\mathrm{AC}$ do tipo não identificadas, foram maiores em relação ao controle negativo. Em agosto, a única alteração encontrada em nível significante foram as pontes cromossômicas. Não houve alteração significante para o IM. Esses resultados indicam que os efluentes de origem variada estão exercendo efeitos nocivos no bioindicador utilizado, sendo importante manter o biomonitoramento e adotar medidas de controle de efluentes. Essas medidas são importantes porque essas águas são utilizadas para abastecimento público, irrigação, entre outras utilidades.

Palavras-chave: poluição de rios; mutagenicidade; teste Allium cepa; aberrações cromossômicas.

\section{Mutagenic potential of pollutants in the water of the Paraíba do Sul river, Tremembé, SP, Brazil, using the Allium cepa test}

\begin{abstract}
The mutagenicity can be related to chromosomic breaks induced by environmental pollutants. The aim of this research was to characterize the mutagenic potential of the pollutants in the water of the Paraíba do Sul river, in Tremembé city, São Paulo State, Brazil, analyzing chromosomal changes in the meristematic cells of Allium cepa, in the summer (April) and winter (August) of 2008. The bulbs were exposed for $72 \mathrm{~h}$ to the treatments: water from river, Hoagland solution (negative control) and $15 \mu \mathrm{g} / \mathrm{L}$ from MMS - methyl methanesulfonate (positive control). In each treatment, three bulbs were exposed and for each bulb, five slides were prepared. For mitotic index (MI) and micronucleus (MN) frequency rate, a total of 2,000 cells per root/slide were analyzed and 100 cells for the chromosome aberrations (CA). In April, the pollutants induced a high mutagenic potential in the meristematic cells of Allium cepa, the frequency rate of $\mathrm{MN}$, stickiness and CA from nonidentified type were greater than the negative control. In August, the only significant change found was the chromosome bridges. There was no significant change for MI. These results

Revista Ambiente \& Água - An Interdisciplinary Journal of Applied Science: v. 6, n. 1, 2011.
\end{abstract}


OLIVEIRA, L. M.; VOLTOLINI, J. C.; BARBÉRIO, A. Potencial mutagênico dos poluentes na água do rio Paraíba do Sul em Tremembé, SP, Brasil, utilizando o teste Allium cepa. Ambi-Agua, Taubaté, v. 6, n. 1, p. 90103, 2011. (doi:10.4136/ambi-agua.176)

indicate that the effluents which have varied sources are inducing harmful effects on the bioindicator, therefore, it is important to keep biomonitoring and adopting effluents control measures. The measures are important because these waters are used primarily for public supply and irrigation.

Keywords: river pollution; mutagenicity; Allium cepa test; chromosomes aberrations.

\section{INTRODUÇÃO}

Resíduos industriais, urbanos e agrícolas são lançados indiscriminadamente nos cursos d'água acrescentando vários contaminantes às águas superficiais e sedimentos (Egito et al., 2007). Esses resíduos são caracterizados como misturas complexas contendo numerosos compostos orgânicos e inorgânicos genotóxicos que muitas vezes não sofrem degradação durante o processo de tratamento de água devido a um alto grau de persistência, alguns são mutagênicos conhecidos (Nielsen e Rank, 1994; Rank e Nielsen, 1998). Metais pesados potencialmente tóxicos lançados na natureza são perigosos e frequentemente indestrutíveis e, mesmo quando precipitados e consequentemente acumulados no fundo de rios, o processo pode ser revertido voltando os metais à sua forma tóxica inicial (Tommasi, 1979). O chorume, um líquido escuro resultante da ação da água das chuvas que percola pelos resíduos orgânicos em decomposição, chega até os rios onde causa depressão no nível de oxigênio e eleva a DBO (Demanda Biológica de Oxigênio) vindo a prejudicar os organismos aeróbios, os quais cedem lugar aos anaeróbios, que liberam $\mathrm{NH}_{3}$, tóxico para muitos organismos (Lima, 1995). Além dos efeitos diretos à saúde, o perigo dos poluentes está no fato de poderem ter efeitos tóxicos ou mutagênicos indiretos e, ao longo do tempo, causar várias doenças como: infertilidade, câncer, arteriosclerose, doenças cardiovasculares, entre outros (Grover e Kaur, 1999).

$\mathrm{O}$ processo de tratamento de água dos mananciais que recebem esgotos de centros urbanos, efluentes industriais, águas residuais da mineração ou o escoamento superficial difuso de bacias hidrográficas, onde se pratica uma agricultura com uso intenso de insumos químicos, não pode ser considerado totalmente eficaz, devido à impossibilidade de eliminação adequada da grande variedade de elementos menores ou traços de substâncias perigosas que podem estar presentes nas águas de consumo (Rebouças, 2006). Torna-se cada vez mais difícil e inviável a análise sistemática da determinação de cada um dos inúmeros componentes químicos que podem comprometer a qualidade da água por meio de procedimento analítico se considerar-se a crescente variedade de produtos sintéticos que podem atingir um manancial (Branco et al., 2006).

O aumento da necessidade pelos recursos hídricos causado pela expansão demográfica na região do Vale do Paraíba faz com que as empresas de saneamento e prefeituras aumentem a demanda no fornecimento de água, não havendo em contrapartida o mesmo para o esgotamento sanitário. Em Tremembé-SP, município do Vale do Paraíba, a água utilizada no abastecimento público, irrigação e outros fins, é captada no rio Paraíba do Sul, o qual, antes de chegar ao município recebe vários efluentes não tratados de cidades vizinhas com elevado índice populacional e industrial que contribuem significativamente com a carga poluidora (Souza Jr., 2004).

Substâncias tóxicas, muitas das quais químicas, promovem a ocorrência de mutações genéticas e aberrações cromossômicas e existe um grande número de protocolos desenvolvidos para detectar essas alterações (Majer et al., 2005).

Para a avaliação, monitoramento e detecção de genotóxicos no ambiente os bioensaios com plantas superiores têm sido recomendados desde a década de 70 (Grant, 1999). Células vegetais geralmente possuem enzimas necessárias para ativação e metabolização de compostos promutagênicos e hidrocarbonetos aromáticos policíclicos (PAHs), como é o caso das células meristemáticas das raízes de Allium cepa (a cebola comum), espécie usada com 
OLIVEIRA, L. M.; VOLTOLINI, J. C.; BARBÉRIO, A. Potencial mutagênico dos poluentes na água do rio Paraíba do Sul em Tremembé, SP, Brasil, utilizando o teste Allium cepa. Ambi-Agua, Taubaté, v. 6, n. 1, p. 90103, 2011. (doi:10.4136/ambi-agua.176)

mais frequência como sistema-teste desde o final da década de 30, quando Levan investigou os efeitos citológicos da colchicina revelando vários efeitos tóxicos e clastogênicos da ação direta dos químicos, sendo posteriormente demonstrado que soluções de vários tipos de sais inorgânicos induzem diferentes tipos de aberrações cromossômicas em células de Allium сера, constituindo-se essa espécie numa valiosa ferramenta de monitoramento ambiental para a detecção do potencial genotóxico das substâncias lançadas no ambiente (Fiskesjö, 1985, 1989; Rank et al., 2002). A mutagenicidade pode estar relacionada com a frequência de quebras cromossômicas, dessa forma, os riscos de eventos mutagênicos podem ser avaliados pela frequência desses danos genéticos (Fiskesjö, 1985).

O teste Allium é bem conhecido e comumente utilizado em laboratórios do mundo inteiro para análise de várias substâncias das quais se deseja conhecer o possível potencial mutagênico, estimado pela frequência de aberrações e quebras cromossômicas indicando riscos de aneuploidia e fornecendo valiosas informações em relação à avaliação de amostras ambientais (Rank e Nielsen, 1993).

Os resultados positivos no teste Allium devem ser considerados como uma indicação de que a amostra testada pode ser um perigo biológico também para os outros organismos (Fiskesjö, 1989), podendo indicar a presença de certas substâncias citotóxicas, genotóxicas ou mutagênicas no ambiente (Smaka-Kincl et al., 1996). A alta sensibilidade do teste Allium determina que contaminações não passem despercebidas, mesmo quando são testadas misturas complexas como no caso de esgotos. É recomendado para uma rápida avaliação da genotoxicidade de efluentes, sendo uma valiosa ferramenta que pode ser usada como padrão em monitoramentos ambientais para se traçar a localização da fonte de contaminação, identificando influências de baixas concentrações de substâncias citotóxicas e genotóxicas em águas naturais (rios ou lagos), os quais são usados como recipientes para efluentes domésticos e industriais e que, posteriormente, têm suas águas utilizadas na agricultura e no abastecimento público (Fiskesjö,1985, 1989; Rank e Nielsen, 1993; Nielsen e Rank, 1994; Smaka-Kincl et al., 1996; Amaral et al., 2007; Barbério et al., 2009).

O teste Allium, combinado com análises químicas, pode ser usado para se conseguir dados com bases científicas para regulamentação das descargas de substâncias potencialmente perigosas, lançadas no ambiente (Nielsen e Rank, 1994). Também mostrou ser sensível nas análises de hidrocarbonetos do petróleo, representando um eficiente modelo para detectar tais contaminações (Leme e Marin-Morales, 2008), podendo ser utilizado em conjunto com outros sistemas-testes para se avaliar a contaminação de águas superficiais por esgotos, lodos de esgotos domésticos e industriais (Gupta et al., 2005), poluentes provenientes de plantações agrícolas (Oberholster et al., 2008) e em extratos aquosos de solos (Cotelle et al., 1999).

A bacia do rio Paraíba do Sul localiza-se no principal eixo econômico do país, que se destaca pela diversidade de seu parque industrial, sobressaindo-se a indústria aeronáutica, a automobilística, a de papel e celulose, a química, a mecânica, a eletroeletrônica e a extrativista, além de centros de pesquisa tecnológica. Na agricultura, predominam as culturas destinadas à pecuária, extensas áreas com o cultivo de eucalipto, além da presença de culturas de arroz, feijão e milho (Cetesb, 2008). A área de drenagem da bacia possui cerca de 55.500 $\mathrm{km}^{2}$, abrangendo os estados de São Paulo, Minas Gerais e Rio de Janeiro.

O rio Paraíba do Sul forma-se no estado paulista pela união dos rios Paraibuna e Paraitinga e o seu comprimento, calculado a partir da nascente do Paraitinga é de mais de $1.100 \mathrm{~km}$. Na região da bacia pertencente ao estado de São Paulo, calcula-se que existam cerca de 4.000 estabelecimentos ligados ao setor industrial e agropecuário e as principais fontes de poluição dos recursos hídricos são os lançamentos de efluentes domésticos e industriais junto com a carga difusa de origem urbana e agrícola. O índice de atendimento em abastecimento de água no estado paulista é de $94,6 \%$ e, em esgotamento sanitário, $89,9 \%$ das populações urbanas são atendidas por rede coletora, das quais 32,3\% possuem tratamento para seus efluentes sanitários (Fundação Coppetec, 2006). 
Em Tremembé (SP), município com 41.159 habitantes em 2009 (CETESB, 2010), a qualidade da água do rio Paraíba do Sul foi classificada como pertencente à classe 2, de acordo com a resolução do CONAMA n 357 de 17 março de 2005, que classifica as águas interiores segundo seus usos preponderantes variando da Classe Especial (a mais nobre) até a Classe 4 (a menos nobre). A elevada carga poluidora lançada pelos municípios de Jacareí, São José dos Campos e Taubaté é a principal causa para a má qualidade da água no trecho de Tremembé, constatando-se baixos níveis de oxigênio dissolvido e níveis de chumbo acima do estabelecido pela legislação (Cetesb, 2008). Souza e Fontanetti (2006) avaliaram a frequência de micronúcleos em sangue periférico da Tilápia do Nilo expostas à água do rio Paraíba do Sul (coletadas durante a estação seca e chuvosa) e detectaram efeitos citotóxicos e mutagênicos. Barbério (2009) e Barbério et al. (2009), desde 2005, biomonitoram a qualidade da água do rio Paraíba do Sul em Tremembé e Aparecida utilizando o teste Allium, desde então, têm encontrado efeitos nocivos ao organismo testado, indicando má qualidade da água do rio.

Este trabalho avaliou o potencial mutagênico da água do rio Paraíba do Sul no município de Tremembé (SP), nas estações chuvosa (abril) e seca (agosto) de 2008.

\section{MATERIAL E MÉTODOS}

\subsection{Local de estudo}

As amostras de água do rio Paraíba do Sul foram coletadas nas coordenadas $22^{\circ} 57^{\prime} 40^{\prime}$ 'S, 45³3'16' 'W no município de Tremembé - SP (Figura 1) em duas épocas distintas: abril (estação chuvosa) e agosto (estação de estiagem) de 2008.



Figura 1. Trecho paulista da bacia do rio Paraíba do Sul. A seta indica o local de coleta.

Fonte: Cetesb (2007).

A amostra de água coletada das margens e meio do rio foi armazenada num galão plástico de 40 L e levada para o Laboratório de Biologia da Universidade de Taubaté (SP) onde foi imediatamente usada para o tratamento dos bulbos de cebola. Os dados de parâmetros físico-químicos e microbiológicos da água do rio Paraíba do Sul, em Tremembé, 
OLIVEIRA, L. M.; VOLTOLINI, J. C.; BARBÉRIO, A. Potencial mutagênico dos poluentes na água do rio Paraíba do Sul em Tremembé, SP, Brasil, utilizando o teste Allium cepa. Ambi-Agua, Taubaté, v. 6, n. 1, p. 90103, 2011. (doi:10.4136/ambi-agua.176)

durante o ano de 2008, foram obtidos a partir do relatório dos Resultados dos Parâmetros e Indicadores de Qualidade das Águas (Cetesb, 2008) para efeito de comparação com os resultados obtidos neste estudo.

\subsection{Ensaio citogenético}

Os experimentos foram conduzidos como descrito por Fiskesjö (1989) no protocolo Invittox $\mathrm{n}^{\mathrm{o}} 8$ com algumas modificações.

Foram colocados 5 bulbos de cebola (Allium cepa) com $6 \mathrm{~cm}$ em média de diâmetro procedentes do comércio local para cada um dos tratamentos. $\mathrm{O}$ anel das raízes primordiais foi cuidadosamente limpo para o experimento. Os bulbos foram colocados em recipientes contendo as soluções de controles positivo e negativo e amostra da água do rio, de modo a poderem enraizar durante um período de $72 \mathrm{~h}$. Após essa fase, os ápices radiculares dos três bulbos com maior desenvolvimento das raízes foram cortados e fixados em etanol/ácido acético glacial numa proporção de $3: 1(\mathrm{v} / \mathrm{v})$ por $5 \mathrm{~min}$. e conservados em tubos eppendorfs contendo $1 \mathrm{~mL}$ de álcool 70\% sob refrigeração.

As pontas das raízes foram submetidas à reação de Feulgen, consistindo de hidrólise ácida com $\mathrm{HCl} 4 \mathrm{~N}$ a $24{ }^{\circ} \mathrm{C}$ por 75 min. interrompida com uma rápida lavagem em $\mathrm{HCl} 0,1 \mathrm{~N}$ (gelado), depois imersas por $40 \mathrm{~min}$. em Schiff (corante púrpura nucleofílico), lavadas com água sulfurosa e água destilada posteriormente. Em seguida, foram colocadas sobre lâminas para microscopia junto com uma ou duas gotas de ácido acético $45 \%$, cobertas com lamínulas e esmagadas com leve pressão sobre o material entre lâmina e lamínula. Para a remoção das lamínulas a lâmina foi mergulhada em nitrogênio líquido. As lâminas foram imersas em fast green (corante verde para o citoplasma) com pH 2.7 para contracoloração (Mello e Vidal, 1980), lavadas em água destilada, secas ao ar, diafanizadas em xilol por 5 min. e montadas com bálsamo do Canadá.

A análise das lâminas foi realizada em microscópio de luz com aumento de 400x ou 1000x quando necessário.

\subsection{Controles}

Para o controle positivo foram usados $15 \mu \mathrm{g} / \mathrm{L}$ de MMS (Metilmetanossulfonato - CAS\# 66273), substância capaz de promover alterações celulares como aberrações cromossômicas e formação de micronúcleos. Esse tipo de agente se caracteriza por sua reatividade com os centros nucleofílicos no DNA, promovendo alquilação nas bases ou no grupo fosfato (Swain e Scott, 1953; Vogel, 1982). No controle negativo, a solução nutritiva de Hoagland (Hoagland e Arnon, 1950) foi empregada.

\subsection{Análise estatística}

A média e o erro padrão (EP) foram obtidos pela contagem de 5 raízes provenientes de cada bulbo e cada grupo experimental foi composto por 3 bulbos.

As aberrações cromossômicas (AC) foram determinadas pela contagem de 500 células mitóticas por bulbo (100/raiz), 1.500 por tratamento.

$\mathrm{O}$ índice mitótico (IM) e micronúcleos (MN) foram avaliados pela análise de aproximadamente 2.000 células/raiz, $10.000 / \mathrm{bulbo}$, portanto 30.000 células por tratamento.

Os dados de frequências de AC, fases mitóticas, IM, MN e número total de células aberrantes foram comparados entre os tratamentos (Tremembé abril/08 e agosto/08 com controle negativo) utilizando teste estatístico Kruskal-Wallis. As análises foram realizadas no software statsdirect (versão 2.7.7). 


\section{RESULTADOS E DISCUSSÃO}

Foram observados seis tipos de aberrações cromossômicas (AC): pontes, anáfases com multipolaridades, c-mitoses, stickiness, desgarrados e "não identificadas - NI". Os micronúcleos foram analisados separadamente, durante o período interfásico (Figura 2).
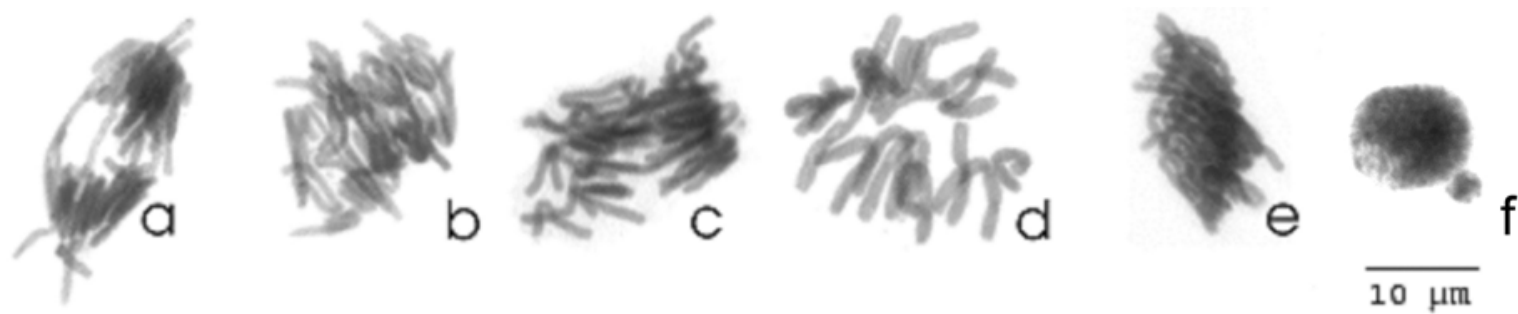

Figura 2. Exemplos de anomalias cromossômicas encontradas em células das raízes de Allium cepa tratadas com água do rio Paraíba do Sul coletada no mês de abril em 2008: a) pontes, b) NI, c) multipolaridade, d) c-mitose, e) stickiness, f) micronúcleo.

O primeiro mecanismo de ação dos agentes genotóxicos é promover lesões no DNA (oxidação e dimerização de bases, adutos de DNA, entre outras). Essas lesões podem ter 3 destinos: reparo, alterações irreversíveis e morte celular (Majer et al., 2005). Os danos genéticos detectados neste estudo são indicativos da presença de substâncias clastogênicas (indutoras de quebras) nas amostras testadas. Classicamente os $\mathrm{MN}$ e as pontes cromossômicas são exemplos desse tipo de mecanismo. Outro mecanismo bastante frequente na indução de variados tipos de $\mathrm{AC}$ também observados neste estudo corresponde à falhas no processo de disjunção dos cromossomos durante a divisão celular, efeito promovido por substâncias aneugênicas - aquelas que interferem na formação do fuso acromático. As anomalias mitóticas como c-mitoses e stickiness (cromossomos pegajosos) podem surgir por processos aneugênicos ou mutações em proteínas importantes na compactação da cromatina. As c-mitoses se originam quando há inativação do fuso acromático de modo que os cromossomos fiquem dispersos na célula (Levan, 1938), muitas substâncias químicas, como as presentes em pesticidas, podem promover esse efeito.

Quanto às alterações nas células, foi observado que a água do rio, em abril, revelou um alto potencial mutagênico quando comparado ao controle negativo (Tabela 1), tanto na frequência de anomalias do tipo stickiness e outras denominadas NI, assim como a frequência de micronúcleos, indicando a presença de contaminantes que promoveram genotoxicidade em células de Allium cepa (Figura 3). A amostra do mês de agosto teve uma diminuição dos efeitos genotóxicos em relação ao tratamento de abril, mas quando comparada ao controle negativo, houve também um aumento das anomalias do tipo ponte. Pode-se inferir que a água do rio possui substâncias nocivas aos organismos que vivem nesse ambiente e que o potencial mutagênico dos poluentes na água varia em função do tempo, dependendo das descargas vindas dos efluentes. Fatores como a sazonalidade, vazão e índice de chuva podem influenciar a concentração de poluentes na água. Alguns estudos, inclusive no rio Paraíba do Sul, sugerem a influência da sazonalidade na indução de efeitos genotóxicos (MN) (Lemos e Erdtmann, 2000; Souza e Fontanetti, 2006). A variação na sazonalidade é um fator que pode influenciar significantemente a frequência de danos genéticos e promover alterações fisiológicas nos organismos expostos. Essa variação pode sofrer alterações de acordo com o nível de poluição em determinado local (Ruiz et al., 1992; Hayashi et al., 1998). Mesmo com uma área de drenagem de $14.444 \mathrm{~km}^{2}$, vazão média de $216 \mathrm{~m}^{3} / \mathrm{s}$ e mínima de $72 \mathrm{~m}^{3} / \mathrm{s}$, a água do rio Paraíba do Sul recebe toneladas (167.003 kg/dia) de resíduos (Cetesb, 2008) que não são dispersos e cujos efeitos podem ser detectados por meio de bioensaios. 
OLIVEIRA, L. M.; VOLTOLINI, J. C.; BARBÉRIO, A. Potencial mutagênico dos poluentes na água do rio Paraíba do Sul em Tremembé, SP, Brasil, utilizando o teste Allium cepa. Ambi-Agua, Taubaté, v. 6, n. 1, p. 90103, 2011. (doi:10.4136/ambi-agua.176)

A anomalia do tipo stickiness, foi a mais frequente na amostra do rio coletada em abril, esta mostrou frequência similar ao controle positivo, um conhecido agente alquilante promotor de quebras no DNA, indicando alta genotoxicidade nas amostras testadas. Esses resultados estão de acordo com estudos de outros autores para situações diversas (SmakaKincl et al., 1996; Amaral et al., 2007; Egito et al., 2007; Türkoğlu, 2007, Barbério, 2009). A presença desse tipo de anomalia é indicativa de alto teor de toxicidade que promove danos irreversíveis à célula, conduzindo-a, portanto, à morte celular (Fiskesjö, 1985, 1989; Türkoğlu, 2007).

Tabela 1. Frequência de alterações microscópicas (média \pm erro padrão) nas células radiculares de Allium cepa tratadas com água do rio Paraíba do Sul na cidade de Tremembé - SP.

\begin{tabular}{lrrrr}
\hline & $\begin{array}{c}\text { Rio Paraíba } \\
\text { Tremembé } \\
\text { abril 2008 }\end{array}$ & $\begin{array}{c}\text { Rio Paraíba } \\
\text { Tremembé } \\
\text { agosto 2008 }\end{array}$ & $\begin{array}{c}\text { Controle } \\
\text { negativo }\end{array}$ & $\begin{array}{c}\text { Controle } \\
\text { positivo }\end{array}$ \\
\hline Micronúcleos & $5,13 \pm 0,88^{*}$ & $0,27 \pm 0,07$ & $0,33 \pm 0.18$ & $7,53 \pm 1,99^{*}$ \\
Stickiness & $24,00 \pm 3,52^{*}$ & $6,60 \pm 0,53$ & $6,00 \pm 2,42$ & $23,27 \pm 4,76^{*}$ \\
Desgarrados & $0,27 \pm 0,13$ & $0,40 \pm 0,12$ & $0,47 \pm 0,18$ & $1,93 \pm 0,87$ \\
Pontes & $1,00 \pm 0.23$ & $5,00 \pm 1,01^{*}$ & $1,47 \pm 0.53$ & $1,27 \pm 0.35$ \\
C-mitoses & $4,40 \pm 0,83$ & $1,87 \pm 0,94$ & $1,60 \pm 0,20$ & $4,53 \pm 1,27$ \\
Anáfases Multipolares & $0,33 \pm 0,18$ & $2,07 \pm 0,94$ & $0,87 \pm 0,24$ & $0,80 \pm 0,20$ \\
Outras (NI) & $10,07 \pm 0,55^{*}$ & $0,53 \pm 0.13$ & $1,73 \pm 0,24$ & $11,80 \pm 2,10^{*}$ \\
$\mathrm{~N}^{\mathrm{o}}$ Total de células anômalas & $40,07 \pm 3,77^{*}$ & $17,07 \pm 2,63$ & $12,13 \pm 1,83$ & $42,93 \pm 2,90^{*}$ \\
\hline
\end{tabular}

Nota: Para cada tratamento foram utilizadas 5 raízes por bulbo e 3 bulbos por amostra de água. Para a análise de anomalias cromossômicas foram contadas 100 células em metáfases, anáfases e telófases por raiz. Para a análise de micronúcleos foram contadas em média 2.000 células interfásicas por raiz. Resultados significantes (teste de Kruskal-Wallis; $\alpha<0.05$ ) estão indicados por * quando comparados com o controle negativo.

Barbério (2009) detectou efeito genotóxico significativo observado nesse ponto de coleta realizado em agosto de 2007, sendo que a presença de micronúcleos, stickiness, pontes cromossômicas, c-mitoses, anáfase com multipolaridades, outras $\mathrm{AC}$ e número total de células anômalas apresentaram aumento significativo.

A frequência de $\mathrm{MN}$, observada nas células do meristema radicular de A. cepa foi significativa para o ponto amostrado somente em abril (2008), indicando a presença de substâncias clastogênicas e/ou aneugênicas (inibidoras das fibras do fuso acromático) (Grover e Kaur, 1999; Egito et al., 2007; Barbério, 2009).

O IM e fases do ciclo celular em amostras coletadas nos meses de abril e agosto de 2008, não diferiram do controle negativo (Tabela 2), atestando uma melhora na qualidade da água em relação ao mês de agosto de 2005, onde foi detectado decréscimo do IM (efeito mitodepressivo) em raízes de $A$. cepa tratadas com água do rio Paraíba do Sul coletadas na cidade de Tremembé. Isso mostra que a citotoxicidade induzida por substâncias presentes nessas amostras interferiram no ciclo celular (Barbério et al., 2009).

Vale ressaltar que estudos com $A$. сера mostram que nem sempre a toxicidade está correlacionada com a genotoxicidade, porque alterações relacionadas com o crescimento da raiz e IM são parâmetros indicativos de citotoxicidade. Por outro lado, alterações como anomalias cromossômicas (stickiness, micronúcleos, pontes cromossômicas, entre outras), indicam genotoxicidade (Fiskesjö, 1985). 
OLIVEIRA, L. M.; VOLTOLINI, J. C.; BARBÉRIO, A. Potencial mutagênico dos poluentes na água do rio Paraíba do Sul em Tremembé, SP, Brasil, utilizando o teste Allium cepa. Ambi-Agua, Taubaté, v. 6, n. 1, p. 90103, 2011. (doi:10.4136/ambi-agua.176)
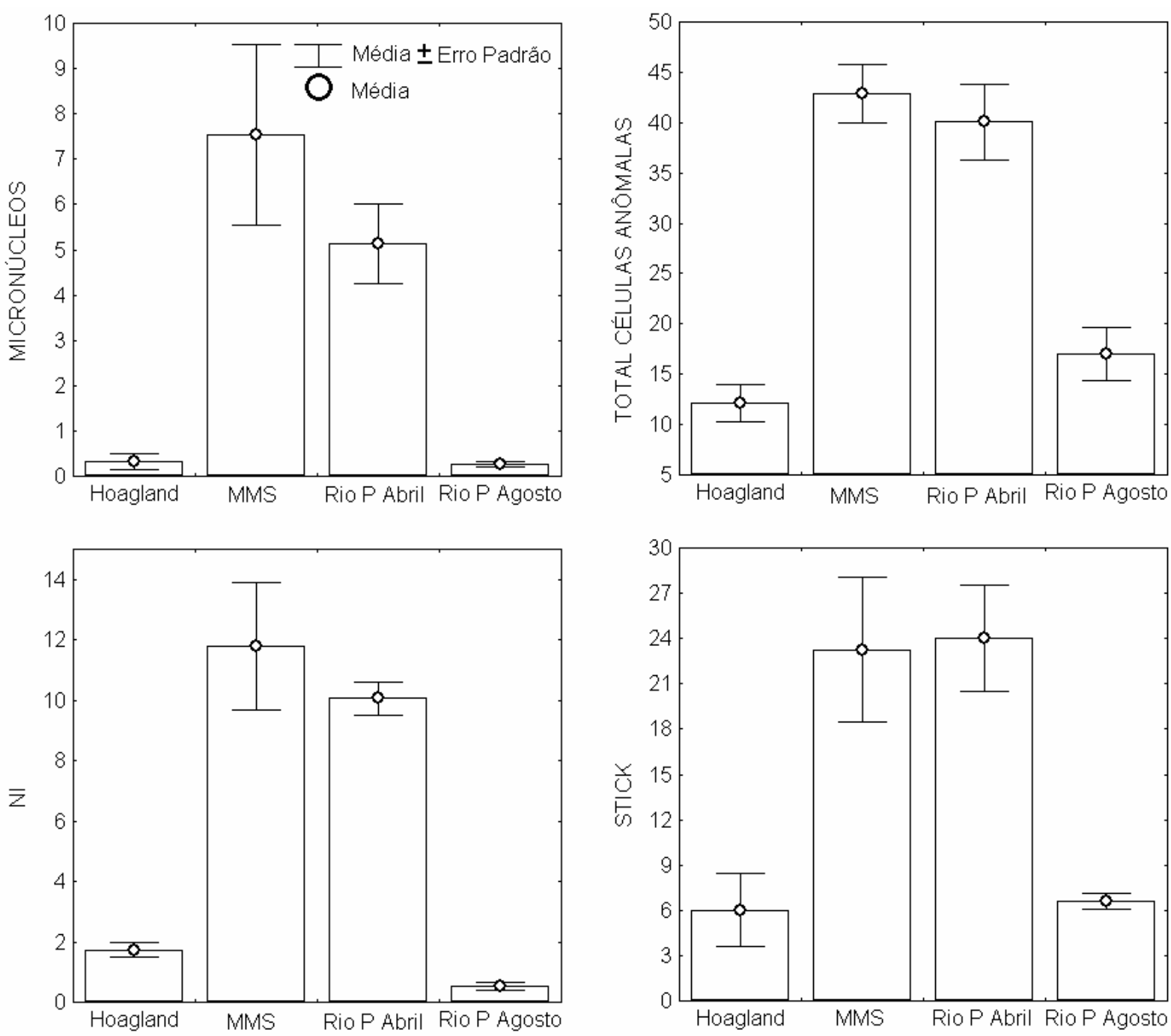

Figura 3. Comparação da frequência de anomalias nas células radiculares de Allium cepa tratadas com água do rio Paraíba do Sul na cidade de Tremembé - SP.

Tabela 2. Frequência dos Índices de Fase do ciclo celular (média \pm erro padrão) em células radiculares de Allium cepa tratadas com água do rio Paraíba do Sul na cidade de Tremembé - SP.

\begin{tabular}{lllll}
\hline & $\begin{array}{c}\text { Rio Paraíba } \\
\text { Tremembé } \\
\text { abril 2008 }\end{array}$ & $\begin{array}{c}\text { Rio Paraíba } \\
\text { Tremembé } \\
\text { agosto 2008 }\end{array}$ & Controle negativo & Controle positivo \\
\hline Intérfases & $1924,40 \pm 5,69$ & $1879,33 \pm 18,97$ & $1890,87 \pm 14,66$ & $1895,13 \pm 10,83$ \\
Prófases & $25,20 \pm 1,33$ & $32,67 \pm 10,42$ & $38,53 \pm 2,26$ & $35,47 \pm 7,25$ \\
Metáfases & $21,93 \pm 2,23$ & $34,80 \pm 7,31$ & $27,80 \pm 8,50$ & $33,80 \pm 0,40$ \\
Anáfases & $10,73 \pm 2,19$ & $23,33 \pm 3,53$ & $15,40 \pm 2,91$ & $13,53 \pm 2,02$ \\
Telófases & $17,73 \pm 2,05$ & $29,87 \pm 1,91$ & $27,40 \pm 4,66$ & $22,07 \pm 2,10$ \\
IM & $75,60 \pm 5,69$ & $120,67 \pm 18,97$ & $109,13 \pm 14,66$ & $104,87 \pm 10,83$ \\
Total de células & & & & \\
analisadas & 30.000 & 30.000 & 30.000 & 30.000 \\
\hline
\end{tabular}

Nota: Para cada tratamento foram utilizadas 5 raízes por bulbo e 3 bulbos por amostra de água. Para a análise do índice de fases foram contadas em média 2.000 células em prófases, metáfases, anáfases e telófases por raiz. 
OLIVEIRA, L. M.; VOLTOLINI, J. C.; BARBÉRIO, A. Potencial mutagênico dos poluentes na água do rio Paraíba do Sul em Tremembé, SP, Brasil, utilizando o teste Allium cepa. Ambi-Agua, Taubaté, v. 6, n. 1, p. 90103, 2011. (doi:10.4136/ambi-agua.176)

As análises físico-químicas, microbiológicas e hidrobiológicas da água do rio Paraíba do Sul indicaram que entre os 34 parâmetros analisados em abril e 33, em agosto, como cromo, mercúrio, chumbo, entre outros, não se acham presentes em níveis acima dos tolerados pela legislação CONAMA 357/2005, com exceção das concentrações de alumínio dissolvido, ferro dissolvido, fósforo total, manganês total, oxigênio dissolvido e E. coli termotolerante. $\mathrm{O}$ Relatório da CETESB revelou, em abril de 2008, 0,2 mg/L de alumínio dissolvido na água coletada no rio Paraíba do Sul em Tremembé (máximo tolerado $=0,1 \mathrm{mg} / \mathrm{L}$ ) (Cetesb, 2008). O efeito citológico mais típico promovido pelo alumínio é a formação de stickiness e pontes cromossômicas (Fiskesjö, 1988). Foram observados 0,51 mg/L (abril) e 0,64 mg/L (agosto) de ferro dissolvido, o normal preconizado pela resolução é de $0,3 \mathrm{mg} / \mathrm{L}$. As concentrações de fósforo e manganês total apresentaram respectivamente, 0,16 e $0,15 \mathrm{mg} / \mathrm{L}$ em agosto (normal $=0,1 \mathrm{mg} / \mathrm{L}$ ). $\mathrm{O}$ oxigênio dissolvido na água do rio em Tremembé nos meses de abril e agosto apresentou valores de 4,0 e 4,3 mg/L, respectivamente, o mínimo requerido é de 5,0 mg/L. Os valores de E. coli termotolerantes em abril e agosto de 2008 foram de 2.500 e 3.200 $\mathrm{UFC} / 100 \mathrm{~mL}$ respectivamente (máximo tolerado $=1.000 \mathrm{UFC} / 100 \mathrm{~mL}$ ) (Cetesb, 2008) (Tabela 3).

As concentrações excedentes podem ser um predicativo à ocorrência de anomalias mitóticas em células de $A$. cepa exposta à água do rio Paraíba do Sul no local e período de coleta.

Vale ressaltar que o referido relatório apresentou resultados de toxicidade negativa no mês de agosto e não realizou tal teste no mês de abril. Para esse parâmetro a CETESB utiliza outros sistemas-teste, como ensaio de toxicidade com a bactéria luminescente $V$. fischeri (Sistema microtox), ensaio de toxicidade crônica com testes com o microcrustáceo Ceriodaphnia dubia e ensaio de mutação reversa (teste AMES). Segundo Chandra et al. (2005), alguns metais mesmo sendo essenciais às plantas e aos animais como é o caso do ferro, quando combinados com metais pesados como, por exemplo, cromo e níquel ou outros compostos orgânicos/inorgânicos podem exercer sinergismo, induzindo uma alta porcentagem de células micronucleadas. Palácio et al. (2005) detectaram que metais pesados contidos em água poluída na presença de vários outros compostos e nutrientes essenciais devido a uma alta demanda bioquímica de oxigênio (DBO) têm suas toxicidades diminuídas em relação aos mesmos metais quando contidos em água limpa, possivelmente devido à formação de complexos químicos que se formaram e foram precipitados, reduzindo a disponibilidade desses metais dissolvidos na água. Possivelmente, a água do rio no mês de agosto poderia ter recebido uma carga orgânica de origem doméstica mais alta, disponibilizando uma maior quantia de nutrientes na água e elevando a $\mathrm{DBO}$, reagindo com compostos tóxicos e precipitando-se no fundo do rio. 
OLIVEIRA, L. M.; VOLTOLINI, J. C.; BARBÉRIO, A. Potencial mutagênico dos poluentes na água do rio Paraíba do Sul em Tremembé, SP, Brasil, utilizando o teste Allium cepa. Ambi-Agua, Taubaté, v. 6, n. 1, p. 90103, 2011. (doi:10.4136/ambi-agua.176)

Tabela 3. Resultados dos parâmetros e indicadores de qualidade das águas.

\begin{tabular}{|c|c|c|c|c|c|c|c|c|}
\hline \multirow{2}{*}{ Parâmetro } & \multirow{2}{*}{ Unidade } & \multirow{2}{*}{ CONAMA } & $21 / 2$ & $3 / 4$ & $18 / 6$ & $19 / 8$ & $2 / 10$ & $3 / 12$ \\
\hline & & & 9:45 & 9:35 & 9:55 & 9:20 & 9:30 & 10:05 \\
\hline \multicolumn{9}{|c|}{ Parâmetro: Campo } \\
\hline Chuva $24 \mathrm{~h}$ & - & & $\operatorname{sim}$ & $\operatorname{sim}$ & não & não & $\operatorname{sim}$ & $\operatorname{sim}$ \\
\hline Coloração & - & & $\begin{array}{c}\text { transparent } \\
\mathrm{e}\end{array}$ & $\begin{array}{c}\text { transparent } \\
\mathrm{e}\end{array}$ & $\begin{array}{c}\text { transparent } \\
\mathrm{e}\end{array}$ & $\begin{array}{c}\text { transparent } \\
\mathrm{e}\end{array}$ & $\begin{array}{c}\text { transparent } \\
\mathrm{e}\end{array}$ & $\begin{array}{c}\text { transparent } \\
\mathrm{e}\end{array}$ \\
\hline $\mathrm{pH}$ & U.pH & entre 6 e 9 & 6,6 & 6,6 & 6,7 & 6,6 & 6,5 & 6,6 \\
\hline Temp. Água & ${ }^{\circ} \mathrm{C}$ & & 26 & 24 & 20 & 21 & 21 & 25 \\
\hline Temp. Ar & ${ }^{\circ} \mathrm{C}$ & & 30 & 25 & 20 & 21 & 21 & 27 \\
\hline \multicolumn{9}{|c|}{ Parâmetro: Físico-Químicos } \\
\hline Absorb. no UV & - & & 0,172 & 0,125 & 0,118 & 0,1 & 0,09 & 0,125 \\
\hline Aluminio Dissolv. & $\mathrm{mg} / \mathrm{L}$ & máx. 0,1 & $* 0,3$ & $* 0,2$ & ${ }^{*} 0,22$ & 0,06 & $<0,1$ & $* 0,12$ \\
\hline Cádmio Total & $\mathrm{mg} / \mathrm{L}$ & máx. 0,001 & $<0,0001$ & 0,0002 & $<0,0001$ & $\mathrm{i}<0,002$ & $<0,0001$ & $<0,0001$ \\
\hline Chumbo Total & $\mathrm{mg} / \mathrm{L}$ & máx. 0,01 & 0,004 & 0,003 & 0,004 & $<0,01$ & $<0,002$ & $<0,002$ \\
\hline Cloreto Total & $\mathrm{mg} / \mathrm{L}$ & máx. 250 & 5,2 & 8,2 & 6,1 & 6,6 & 3,1 & 6 \\
\hline Cobre Dissolv. & $\mathrm{mg} / \mathrm{L}$ & máx. 0,009 & $<0,004$ & $<0,004$ & $<0,004$ & $<0,004$ & $<0,009$ & $<0,009$ \\
\hline COD & $\mathrm{mg} / \mathrm{L}$ & & 3,77 & 5,31 & 8,53 & 5,02 & 3,68 & 5,02 \\
\hline Condutividade & $\mu \mathrm{S} / \mathrm{cm}$ & & 104 & 130 & 105 & 110 & 78 & 101 \\
\hline Cor Verdadeira & $\mathrm{mg} \mathrm{Pt} / \mathrm{L}$ & máx. 75 & 25 & 26 & 18 & 21 & 12 & 25 \\
\hline Cromo Total & $\mathrm{mg} / \mathrm{L}$ & máx. 0,05 & & $<0,002$ & $<0,002$ & & & \\
\hline DBO $(5,20)$ & $\mathrm{mg} / \mathrm{L}$ & máx. 5 & $<2$ & $<2$ & $<3$ & $<2$ & $<2$ & $<2$ \\
\hline Fenóis Totais & $\mathrm{mg} / \mathrm{L}$ & máx. 0,003 & $<0,002$ & $<0,002$ & $<0,002$ & $<0,003$ & $<0,003$ & $<0,003$ \\
\hline Ferro Dissolv. & $\mathrm{mg} / \mathrm{L}$ & máx. 0,3 & ${ }^{*} 0,31$ & * 0,51 & ${ }^{*} 0,38$ & * 0,64 & $<0,1$ & * 0,48 \\
\hline Fósforo Total & $\mathrm{mg} / \mathrm{L}$ & máx. 0,1 & $* 0,12$ & 0,07 & 0,1 & * 0,16 & 0,07 & 0,03 \\
\hline Manganês Total & $\mathrm{mg} / \mathrm{L}$ & máx. 0,1 & 0,05 & 0,07 & 0,08 & $* 0,15$ & 0,04 & 0,08 \\
\hline Mercúrio Total & $\mathrm{mg} / \mathrm{L}$ & máx. 0,0002 & $<0,0002$ & $<0,0002$ & $<0,0002$ & $<0,0002$ & $<0,0002$ & $<0,0002$ \\
\hline N. Amoniacal & $\mathrm{mg} / \mathrm{L}$ & máx. 3,7 & 0,11 & 0,19 & 0,18 & 0,19 & 0,13 & 0,26 \\
\hline Níquel Total & $\mathrm{mg} / \mathrm{L}$ & máx. 0,025 & $<0,008$ & $<0,008$ & $<0,008$ & $<0,008$ & $<0,02$ & $<0,02$ \\
\hline Nitrato & $\mathrm{mg} / \mathrm{L}$ & máx. 10 & 0,31 & 0,31 & 0,44 & 0,69 & 0,36 & 0,41 \\
\hline Nitrito & $\mathrm{mg} / \mathrm{L}$ & máx. 1 & 0,011 & 0,032 & 0,023 & 0,038 & 0,016 & 0,055 \\
\hline NKT & $\mathrm{mg} / \mathrm{L}$ & & 0,65 & 0,63 & 0,49 & 0,77 & 0,31 & 0,88 \\
\hline OD & $\mathrm{mg} / \mathrm{L}$ & mínimo 5 & * 4 & * 4 & * 4,9 & * 4,3 & * 4,8 & * 3,6 \\
\hline Óleos e graxas & $\mathrm{mg} / \mathrm{L}$ & & $<10$ & $<10$ & $<10$ & $<10$ & $<10$ & $<10$ \\
\hline Pot. Form. THM & $\mu g / L$ & & 583 & & 273 & 381 & & 409 \\
\hline $\begin{array}{c}\text { Sol. Dissolv. } \\
\text { Total }\end{array}$ & $\mathrm{mg} / \mathrm{L}$ & máx. 500 & 136 & 152 & 120 & 86 & 118 & $<50$ \\
\hline Sol. Total & $\mathrm{mg} / \mathrm{L}$ & & 156 & 162 & 138 & 98 & 130 & 98 \\
\hline Sol. Volátil Total & $\mathrm{mg} / \mathrm{L}$ & & 66 & 20 & 38 & 28 & 66 & $<50$ \\
\hline Subst. Tensoat. & $\mathrm{mg} / \mathrm{L}$ & máx. 0,5 & $<0,01$ & 0,25 & $<0,01$ & $<0,01$ & $<0,01$ & $<0,01$ \\
\hline Sulfato Total & $\mathrm{mg} / \mathrm{L}$ & máx. 250 & 18 & 21 & 14 & 15 & 12 & 15 \\
\hline Turbidez & UNT & máx. 100 & 49 & 15 & 24 & 14 & 17 & 22 \\
\hline Zinco Total & $\mathrm{mg} / \mathrm{L}$ & máx. 0,18 & $<0,008$ & $<0,008$ & $<0,008$ & $<0,008$ & 0,03 & $<0,02$ \\
\hline \multicolumn{9}{|c|}{ Parâmetro: Microbiológico } \\
\hline Coli Termo & UFC/100 mL & máx. 1000 & * 5400 & * 2500 & 700 & * 3200 & * 4800 & * 2800 \\
\hline \multicolumn{9}{|c|}{ Parâmetro: Ecotoxicológico } \\
\hline Toxicidade & & não tóxico & não tóxico & & & não tóxico & & \\
\hline \multicolumn{9}{|c|}{ Parâmetro: Hidrobiológicos } \\
\hline Clorofila-a & $\mu g / L$ & máx. 30 & 0,3 & 0,27 & 1,07 & 0,53 & 0,8 & $<0,1$ \\
\hline Feofitina-a & $\mu \mathrm{g} / \mathrm{L}$ & & 1,37 & 1,23 & 0,43 & 0,78 & 1,07 & 2,25 \\
\hline
\end{tabular}

Nota: Código do ponto: 00SP02695PARB02490; Classe: 02; Ano: 2008; UGRHI: Paraíba do Sul; Local: rio Paraíba do Sul na captação da Sabesp em Taubaté. (*) Não atendimento aos padrões de qualidade da resolução CONAMA 357/05. (i) Conformidade indefinida quanto ao limite da classe, devido à análise laboratorial não ter atingido os limites legais. UFC - Unidade Formadora de Colônia.

Fonte: Cetesb (2008). 


\section{CONCLUSÃO}

Neste estudo, foi possível detectar a existência de um potencial genotóxico decorrente da presença de substâncias tóxicas na água do rio Paraíba do Sul no local e épocas amostradas. Embora para a pesquisa tenham sido utilizadas duas amostras apenas, sugere-se interferência sazonal.

Devido à importância em se preservar os recursos naturais, em especial este importante rio brasileiro, fazem-se necessários estudos de biomonitoramento de modo a auxiliar e contribuir com redes de monitoramento e ações de manejo.

\section{REFERÊNCIAS BIBLIOGRÁFICAS}

AMARAL, A. M.; BARBÉRIO, A.; VOLTOLINI, J. C.; BARROS, L. Avaliação preliminar da citotoxicidade e genotoxicidade da água na bacia do rio Tapanhon (SP-Brasil) através do teste Allium (Allium cepa). Revista Brasileira de Toxicologia, São Paulo, v. 20, n.1/2, p. 65-71, 2007.

BARBÉRIO, A. Efeitos citotóxicos e genotóxicos no meristema radicular de Allium cepa exposta à água do rio Paraíba do Sul - estado de São Paulo - regiões de Tremembé e Aparecida. 2009. 98f. Dissertação (Doutorado em Biologia Celular e Estrutural) Universidade Estadual de Campinas, Campinas, 2009.

BARBÉRIO, A.; BARROS, L.; VOLTOLINI, J. C.; MELlO, M. L. S. Evaluation of the cytotoxic and genotoxic potential of water from the Brazilian river Paraíba do Sul with the Allium cepa test. Brazilian Journal of Biology, São Carlos, v. 69, n. 3, p. 837-842, 2009.

BRANCO, S. M.; AZEVEDO, S. M. F. O.; TUNDISI, J. G. Água e saúde humana. In: REBOUÇAS, A. C.; BRAGA, B.; TUNDISI, J. G. Águas doces no Brasil: capital ecológico, uso e conservação. 3. ed. São Paulo: Escrituras, 2006. p. 241-267.

CHANDRA, S.; CHAUHAN, L. K. S.; MURTHY, R. C.; SAXENA, P. N.; PANDE, P. N.; GUPTA, S. K. Comparative biomonitoring of leachates from hazardous solid Waste of two industries using Allium test. Science of the Total Environment, Leiden, v. 347, n. $1 / 3$, p. 46-52, 2005.

http://dx.doi.org/10.1016/j.scitotenv.2005.01.002

COMPANHIA DE TECNOLOGIA DE SANEAMENTO AMBIENTAL - CETESB. Relatório de qualidade das águas interiores do estado de São Paulo 2007. São Paulo: CETESB, 2007. p. 85.

COMPANHIA DE TECNOLOGIA DE SANEAMENTO AMBIENTAL - CETESB. Relatório de qualidade das águas interiores do estado de São Paulo 2007. São Paulo: CETESB, 2008. 537 p.

COMPANHIA DE TECNOLOGIA DE SANEAMENTO AMBIENTAL - CETESB. Relatório de qualidade das águas interiores do estado de São Paulo 2009. São Paulo: CETESB, 2010. 310 p.

CONSELHO NACIONAL DO MEIO AMBIENTE - CONAMA. Resolução nº 20, de 18 de junho de 1986. In: PINTO, W. de D. (Org.). Resoluções CONAMA anotada. Brasília: Fórum, 2002. p. 115-139. 
OLIVEIRA, L. M.; VOLTOLINI, J. C.; BARBÉRIO, A. Potencial mutagênico dos poluentes na água do rio Paraíba do Sul em Tremembé, SP, Brasil, utilizando o teste Allium cepa. Ambi-Agua, Taubaté, v. 6, n. 1, p. 90103, 2011. (doi:10.4136/ambi-agua.176)

CONSELHO NACIONAL DO MEIO AMBIENTE - CONAMA. Resolução nº 357, de 17 de março de 2005. Legislação Federal e Marginalia, Brasília, v. 69, n. 3, p. 1631-1661, 2005 .

COTELLE, S.; MASFARAUD, J. F.; FÉRARD, J. F. Assessment of the genotoxicity of contaminated soil with the Allium/Vicia-micronucleus and the Tradescantiamicronucleus assays. Mutation Research, Leiden, v. 426, n. 2, p. 167-171, 1999.

EGITO, L. C. M.; MEDEIROS, M. G.; DE MEDEIROS, S. R. B.; AGNEZ-LIMA, L. F. Cytotoxic and genotoxic potential of surface water from the Pitimbu river, northeastern/RN Brazil. Genetics and Molecular Biology, Ribeirão Preto, v. 30, n. 2, p. 435-441, 2007.

FISKESJÖ, G. The Allium test as a standard in environmental monitoring. Hereditas, New Jersey, v. 102, n. 1, p. 99-112, 1985.

FISKESJÖ, G. The Allium test - an alternative in environmental studies: the relative toxicity of metal ions. Mutation Research, Leiden, v. 197, n. 1, p. 243-260, 1988.

FISKESJÖ, G. INVITTOX Protocol no 8 - Allium test. Nottingham: Russel and Burch House, 1989.

FUNDAÇÃO COPPETEC. Plano de recursos hídricos da Bacia do Rio Paraíba do Sul : Resumo. Diagnóstico dos Recursos Hídricos. Relatório Final PSR-010-R0. Rio de Janeiro: Laboratório de Hidrologia e Estudos de Meio Ambiente; COPPETEC, 2006. 201 p. Relatório Contratual R-7 - Novembro.

GRANT, W. F. Higher plant assays for the detection of chromosomal aberrations and gene mutations - a brief historical background on their use for screening and monitoring environmental chemicals. Mutation Research, Leiden, v. 426, n. 2, p. 107-112, 1999.

GROVER, I. S.; KAUR, S. Genotoxicity of wastewater samples from sewage and industrial effluent detected by the Allium root anaphase aberration and micronucleus assays. Mutation Research, Leiden, v. 426, n. 2, p. 183-188, 1999.

GUPTA, S. K.; SRIVASTAVA, R.; KUMAR, D. Bioremediation of municipal sludge by vermitechnology and toxicity assessment by Allium cepa. Bioresource Technology, Leiden, v. 96, n. 17, p. 1867-1871, 2005.

HAYASHI, M.; UEDA, T.; UYENO, K.; WADA, K.; KINAE, N.; SAOTOME, T. et al. Development of genotoxicity assay systems that use aquatic organisms. Mutation Research, Leiden, v. 399, n. 2, p. 125-133, 1998.

HOAGLAND, D. R.; ARNON, D. I. The water: culture method for growing plants without soil. Berkeley: California Agicultural Experiment Station, 1950. 32 p.

LEME, D. M.; MARIN-MORALES, M. A. Chromosome aberration and micronucleus frequencies in Allium cepa cells exposed to petroleum polluted water: a case study. Mutation Research, Leiden, v. 650, n. 1, p. 80-86, 2008.

LEMOS, C. T.; ERDTMANN, B. Cytogenetic evaluation of aquatic genotoxicity in human cultured lymphocytes. Mutation Research, Leiden, v. 467, n. 1, p. 1-9, 2000.

LEVAN, A. Effect of colchicines on root mitosis in Allium. Hereditas, New Jersey, v. 24, n. 1, p. 471-486, 1938.

LIMA, L. M. Q. Lixo: tratamento e biorremediação. 3. ed. São Paulo: Hemus, 1995. 265 p. 
MAJER, B. J.; GRUMMT, T.; UHL, M.; KNASMÜLLER, S. Use of plant bioassays for the detection of genotoxins in the aquatic environment. Acta Hydrochimica Hydrobiologica, Weinheim, v. 33, n. 1, p. 45-55, 2005.

http://dx.doi.org/10.1002/aheh.200300557

MELlO, M. L. S.; VIDAL, B. C. Práticas de biologia celular. São Paulo: Edgard Blücher/Funcamp, 1980. p. 57-58.

NIELSEN, M. H.; RANK, J. Screening of toxicity and genotoxicity in wastewater by the use of the Allium test. Hereditas, New Jersey, v. 121, n. 3, p. 249-254, 1994.

OBERHOLSTER, P. J.; BOTHA, A. M.; CLOETE, T. E. Biological and chemical evaluation of sewage water pollution in the Rietvlei nature reserve wetland area, South Africa. Environmental Pollution, Leiden, v. 156, n. 1, p. 184-192, 2008. http://dx.doi.org/10.1016/j.envpol.2007.12.028

PALÁCIO, S. M.; ESPINOZA-QUIÑONES, F. R.; GALANTE, R. M.; ZENATTI, D. C.; SEOLATTO, A. A.; LORENZ, E. K. et al. Correlation between heavy metal ions (Copper, Zinc, Lead) concentrations and root length of Allium cepa L. in polluted river water. Brazilian Archives of Biology and Technology, Curitiba, v. 48, n. Special 1, p. 191-196, 2005.

RANK, J.; NIELSEN, M. H. A modified Allium test as a tool in the screening of the genotoxicity of complex mixtures. Hereditas, New Jersey, v. 118, n. 1, p. 49-53, 1993.

RANK, J.; NIELSEN, M. H. Genotoxicity testing of wastewater sludge using the Allium cepa anaphase-telophase chromosome aberration assay. Mutation Research, Leiden, v. 418, n. 1-2, p. 113-119, 1998.

RANK, J.; LOPEZ, L. C.; NIELSEN, M. H.; MORETTON, J. Genotoxicity of maleic hydrazide, acridine and DEHP in Allium сера root cells performed by two different laboratories. Hereditas, New Jersey, v. 136, n. 1, p. 13 -18, 2002.

REBOUÇAS, A. C. Água doce no mundo e no Brasil. In: REBOUÇAS, A. C. Águas doces no Brasil: capital ecológico, uso e conservação. 3. ed. São Paulo: Escrituras, 2006. p. 01-60.

RUIZ, E. F.; RABAGO, V. M. E.; LECONA, S. U.; PEREZ, A. B.; MA, T. H. Tradescantiamicronucleus (Trad-MCN) bioassay on clastogenicity of wastewater and in situ monitoring. Mutation Research, Leiden, v. 270, n. 1, p. 45-51, 1992.

SMAKA-KINCL, V.; STEGNAR, P.; LOVKA, M.; TOMAN, M. J. The evaluation of waste, surface and ground water quality using the Allium test procedure. Mutation Research, Leiden, v. 368, n. 3/4, p. 171-179, 1996.

http://dx.doi.org/10.1016/S0165-1218(96)90059-2

SOUZA JR., D. I. de. A degradação da bacia do rio Paraíba do Sul. Engevista, Niterói, v. 6, n. 3, p. 99-105, 2004.

SOUZA, T. S.; FONTANETTI, C. S. Micronucleus test and observation of nuclear alterationsin erythrocytes of Nile tilapia exposed to waters affected by refinery effluent. Mutation Research, Leiden, v. 605, n. 2, p. 87-93, 2006.

SWAIN, G. G.; SCOTT, C. B. Quantitative correlation of relative rates: comparison of hydroxide ion and other nucleophilic reagents towards alkyl halides, esters, epoxides and acyl halides. Journal American Chemical Society, Salt Lake, v. 75, n. 1, p. 141147, 1953. 
OLIVEIRA, L. M.; VOLTOLINI, J. C.; BARBÉRIO, A. Potencial mutagênico dos poluentes na água do rio Paraíba do Sul em Tremembé, SP, Brasil, utilizando o teste Allium cepa. Ambi-Agua, Taubaté, v. 6, n. 1, p. 90103, 2011. (doi:10.4136/ambi-agua.176)

TOMMASI, L. R. A degradação do meio ambiente. 4. ed. São Paulo: Nobel, 1979. 169 p.

TÜRKOĞLU, Ş. Genotoxicity of five food preservatives tested on root tips of Allium cepa L. Mutation Research, Leiden, v. 626, n. 1/2, p. 4-14, 2007.

VOGEL, E. W. Assessment of chemically induced genotoxic events. In: Prospectives and limitations. Leiden: The Netherlands University Press, 1982. p. 2-24. 